\title{
A FUNÇÃO DO ESTADO DEMOCRÁTICO DE DIREITO NA EFETIVAÇÃO DOS DIREITOS FUNDAMENTAIS
}

Laura Ferreira Meletti ${ }^{1}$

Matheus Felipe Galera de Oliveira Costa ${ }^{2}$

\begin{abstract}
Resumo
O Estado Democrático de Direito edifica-se sobre os preceitos da dignidade da pessoa humana, dos direitos e garantias fundamentais, do bem-estar social e dos direitos humanos. Assim, uma vez que o Estado Brasileiro figura neste contexto, objetiva-se demonstrar seu dever de atuar em prol de tais direitos, zelando pela coisa pública e pela vida digna de seus cidadãos. Tendo em vista, principalmente, a Constituição de 1988 analisa-se o Direito positivado no que tange às funções designadas ao Estado, bem como o Direito oriundo de outras fontes e sua atuação perante à população. Ademais, faz-se revisão bibliográfica no que diz respeito aos direitos fundamentais, às funções do Estado e às interseções entre estes. A necessidade da concretização do ideal democrático é pressuposto do Estado Democrático de Direito, carregando como requisitos para tanto a consumação dos direitos e garantias fundamentais, a consciência dos aspectos individuais e sociais, bem como o debate em torno de questões de interesse pessoal e coletivo. Frente a isso, numa sociedade que almeja a realização democrática, os requisitos essenciais ocupam posição de destaque na Constituição, positivados na forma de regras e princípios constitucionais. Destarte, observa-se a íntima relação de interdependência entre o escopo democrático e o texto constitucional. Ainda que o texto constitucional nacional abranja e proteja as diversas dimensões de direitos fundamentais, muitos destes não são efetivados pelo Estado, deixando grande parte da população às margens de seus próprios direitos. Ademais, a manipulação dos aparatos legais pelo poder Executivo e Legislativo brasileiros, em função de objetivos políticos, econômicos e pessoais, traduz-se como um prejuízo à hermenêutica nacional. Assim, a responsabilização do Estado por ação, direta ou indireta, na precarização de direitos pode e deve ser uma ferramenta da população para exigir que o papel democrático seja respeitado.
\end{abstract}

Palavras-Chave: Estado Democrático de Direito; Direitos fundamentais; Democracia; Direito Constitucional; Abuso de Prerrogativas.

\section{INTRODUÇÃO}

Há tempos, o Estado Democrático de Direito sobre o qual edifica-se a República Federativa do Brasil vem sofrendo graves ameaças, e tendo seus princípios norteadores ignorados e violados pelos membros do governo e de todos os seus órgãos. Comandado por uma elite excludente, o aparato jurídico e legislativo vem sendo utilizado como ferramenta para cercear os chamados direitos e garantias fundamentais. Neste sentido, os detentores do poder político fazem uso de sua posição econômica e hierárquica privilegiada, instrumentalizando o Estado brasileiro em prol de

\footnotetext{
${ }^{1}$ Universidade Estadual de Londrina, laurafmeletti@gmail.com.
}

${ }^{2}$ Universidade Estadual de Londrina, matheus.me@hotmail.com. 
seus próprios benefícios. Ademais, o Direito como reflexo máximo das expressões ideológicas do poder atua em prol da manutenção do status quo, a partir de um ordenamento enrijecido e cristalizado.

Como consequência do controle do poder decisório por parte de uma minoria alinhada ao ideais do neoliberalismo econômico, o Estado Democrático de Direito é constantemente colocada à prova. Acontecimentos recentes como o Projeto de Lei no 6583/2013 - Estatuto da Família evidenciam o abuso de poder dos membros da máquina estatal, travestido de representação de uma suposta "opinião pública". Assim, discursos de ódio são proferidos, mascarados de liberdade de expressão; a minoria dominante abafa as vozes dos majoritários sem poder; e os direitos e garantias imprescindíveis à vida digna ficam em segundo plano.

Frente a isso, o objetivo do presente trabalho é demonstrar a categorização do Estado brasileiro como Estado Democrático de Direito por meio da análise do texto constitucional de 1988 e, consequentemente, os reflexos de tal modelo na atuação perante a população, principalmente no que diz respeito aos direitos fundamentais. Em contraponto, faz-se uma análise da realidade política, econômica e social vivenciada no país, e como essa não apenas influencia, mas acaba por ditar as normas do ordenamento jurídico-normativo nacional em benefício dos interesses dos donos do poder e em detrimento de uma maioria falsamente representada.

\section{A CONSTITUIÇÃO DE 1988 E O NOVO ESTADO BRASILEIRO}

Uma Constituição não pode ser interpretada como um texto exclusivamente jurídico, isento de princípios e diretrizes. Conforme as lições de Bercovici (2004), o texto constitucional, além de seu conteúdo jurídico-normativo, deve também conter disposições políticas, adequadas ao espaço e ao tempo que influenciaram sua redação. É nesse sentido que, em 5 de outubro de 1988, foi promulgada a Constituição da República Federativa do Brasil de 1988 (CF/88).

A Constituição Cidadã, como ficou popularmente conhecida a $\mathrm{CF} / 88$, é fruto de um processo paulatino e contínuo de redemocratização, e representa a ruptura final com o período de 21 anos em que o país teve seu governo tomado pela Ditadura Militar. Tal movimento de reabertura política teve início ainda durante o Regime.

No governo Figueiredo, foi sancionada a Lei $n^{\circ} 6.683 / 79$, que concedeu a anistia a todos os indivíduos que, sob o juízo do regime ditatorial, haviam cometido crimes políticos ou conexos a 
estes. O benefício da anistia foi amplo e abrangeu o período de 02 de setembro de 1961 a 15 de agosto de 1979. Como consequência, a Lei da Anistia de 1979 beneficiou não apenas os membros de grupos opositores ao governo da época, mas também aqueles que cometeram crimes em nome do Estado. Na prática, a anistia ampla, geral e irrestrita representa um perdão aos homicídios, perseguições, sequestros e torturas cometidos pelo próprio aparato estatal.

Posteriormente, a Proposta de Emenda à Constituição no 5 de 1983, de iniciativa do na época Deputado Federal Dante de Oliveira, previa a realização de eleições diretas para Presidente e Vice-Presidente da República. Apesar de integralmente rejeitada, a Emenda Dante de Oliveira surgiu como resposta ao movimento das "Diretas Já" e representou uma guinada rumo à redemocratização. Pela primeira vez em anos, a sociedade brasileira vislumbrou a possibilidade de votar para o cargo máximo do Executivo.

Em 1988, finalmente, o novo texto constitucional marca o advento do Estado Democrático de Direito no Brasil logo em seu art. 1': “A República Federativa do Brasil, formada pela união indissolúvel dos Estados e Municípios e do Distrito Federal, constitui-se em Estado Democrático de Direito [...]". Tal modelo de Estado pode ser conceituado como a síntese entre o Constitucionalismo, oriundo do Estado de Direito, e a Democracia. Nas palavras de Fachin (2008),

\begin{abstract}
O Estado Democrático de Direito formou-se a partir de dois conteúdos: o Estado de Direito e o Estado Democrático. No Estado de Direito, criado pelo liberalismo, tem-se o império da lei, a distribuição do poder estatal, a previsão de direitos fundamentais e a garantia desses direitos. No Estado Democrático, cujo fundamento é a soberania popular, o vocábulo democrático aparece como um qualificativo do Estado. Tal conteúdo deve inspirar não apenas os atos a serem praticados no âmbito do Estado, mas, inclusive, nas relações entre particulares (FACHIN, 2008, p. 179).
\end{abstract}

Historicamente, o Estado de Direito surge em decorrência da luta do povo francês contra os abusos do monarca no Estado Absoluto, a partir da Declaração de Direitos do Homem e do Cidadão (1789), que estabelece limites ao poder dos governantes. Pelo artigo 16 do referido diploma: "a sociedade em que não esteja assegurada a garantia dos direitos nem estabelecida a separação dos poderes não tem Constituição”. Portanto, Estado de Direito é aquele regido por uma Constituição contrária à concentração de poderes e defensora máxima dos direitos fundamentais como razão de ser do Estado (BONAVIDES, 2007).

A inspiração dos preceitos do Estado de Direito é evidente na $\mathrm{CF} / 88$, no que tange, por exemplo, ao princípio da Separação dos Poderes. Além de ser garantida a harmonia e a independência entres os Poderes da União em seu art. $2^{\circ}$, o modelo da tripartição dos Poderes 
(Executivo, Judiciário e Legislativo) é normatizado como cláusula pétrea (art. 60, §4º, III), não podendo ser modificado mediante emenda constitucional.

Sergio Alves Gomes (2002) aborda a questão da democracia em vários aspectos, defendendo a necessidade da concretização do ideal democrático para a plena vida em sociedade. Assim sendo, são descritos os principais requisitos para tal consumação, como a liberdade de pensamento e de expressão, a consciência dos aspectos individuais e sociais, bem como a garantia do debate em torno de questões de interesse pessoal e coletivo, ou seja, a efetivação dos direitos fundamentais. Diante disso, Gomes alega que, numa sociedade que almeja a realização democrática, os requisitos essenciais - a exemplo dos supracitados — ocupam posição de grande relevância na Constituição, sendo positivados na forma de regras e princípios constitucionais. Destarte, observa-se a íntima relação de interdependência entre o escopo democrático e o texto constitucional.

Ademais, o autor coloca que, mesmo existindo vários princípios constitucionais elementares à democracia, todos eles convergem para um único ponto: a pessoa humana e seus direitos fundamentais. Desse modo, a dignidade humana constitui a bússola a ser seguida para a construção do espaço democrático. Por fim, Gomes conclui que a efetiva realização da ideia de democracia postulada pela Constituição depende do respeito aos valores salvaguardados pelos princípios fundamentais: liberdade, justiça e solidariedade. Em suas palavras: "sem solidariedade, impossível a justiça e, na ausência desta, os demais valores não encontram espaço" (2002, p. 26).

Ao ser instituído como um Estado Democrático de Direito, o Estado brasileiro, por meio de seus governantes, possui o dever constitucional de zelar pelos direitos fundamentais, conforme define George Marmelstein (2014) ao traçar um conceito sobre o termo,

Os direitos fundamentais são normas jurídicas, intimamente ligadas à ideia de dignidade da pessoa humana e de limitação do poder, positivadas no plano constitucional de determinado Estado Democrático de Direito, que, por sua importância axiológica, fundamentam e legitimam todo o ordenamento jurídico (MARMELSTEIN, 2014, p. 17).

Os direitos fundamentais são divididos em gerações. Aqueles componentes da primeira geração são o ponto de partida para assegurar a existência dos demais direitos, uma vez que se traduzem nos chamados Direitos Civis e Políticos, a exemplo do direito à liberdade. Tendo sido concebidos num momento de aversão e combate ao Absolutismo, tais direitos são considerados individuais e possuem um caráter anti-Estado, conforme posto: 
Os direitos da primeira geração ou direitos da liberdade têm por titular o indivíduo, são oponíveis ao Estado, traduzem-se como faculdades ou atributos da pessoa e ostentam uma subjetividade que é seu traço mais característico; enfim, são direitos de resistência ou de oposição perante o Estado (BONAVIDES, p. 578, 2019).

Por outro lado, a eficácia dos direitos fundamentais de segunda geração exige forte presença estatal. Inspirados na doutrina socialista, os direitos econômicos, sociais e culturais

[...] impõem diretrizes, deveres e tarefas a serem realizadas pelo Estado, no intuito de possibilitar aos seres humanos melhor qualidade de vida e um nível razoável de dignidade como pressuposto do próprio exercício da liberdade. Nessa acepção, os direitos fundamentais de segunda geração funcionam como uma alavanca ou catapulta capaz de proporcionar o desenvolvimento do ser humano, fornecendo-se as condições básicas para gozar, de forma, efetiva, a tão necessária liberdade (MARMELSTEIN, 2014, p. 48).

Por final, para encerrar as três concepções clássicas, tem-se os direitos fundamentais de terceira geração. Nesta categoria, o rol de quem se enquadra como titular destes direitos é mais amplo que nas gerações anteriores. Enquanto a primeira geração é tida como a dos direitos individuais e a segunda pertencente a uma coletividade específica, os direitos da fraternidade ou solidariedade são voltados para toda a humanidade (MARMELSTEIN, 2014, p. 50).

Quanto ao direito pátrio, a CF/88 dispõe em seu Título II acerca dos direitos e garantias fundamentais. Apesar de serem positivadas juntamente, as expressões não possuem o mesmo significado. De acordo com David Araujo e Nunes Júnior (2014), os direitos e as garantias fundamentais são distintos por causa da finalidade: "Enquanto os direitos teriam por nota de destaque o caráter declaratório ou enunciativo, as garantias estariam marcadas pelo seu caráter instrumental, vale dizer, seriam os meios voltados para a obtenção ou reparação dos direitos violados" (ARAUJO; JÚNIOR, 2014, p. 150).

Assim sendo, o Estado brasileiro configura-se como Estado Democrático e, como tal, deve rigorosamente cumprir o disposto em sua Carta Magna, primando pela promoção, proteção e efetivação dos Direitos e Garantias fundamentais de toda sua população.

\section{ESTADO DEMOCRÁTICO DE DIREITO: UTOPIA OU REALIDADE?}

Em que se pese o posto Estado Democrático de Direito brasileiro, explanado já no primeiro artigo da $\mathrm{CF} / 88$, o cenário nacional não condiz com as promessas da lei. O Brasil vivencia, há tempos, um sistema normativo excludente, política e economicamente, e favorecedor das classes 
mais abastadas da sociedade em detrimento daqueles que não detêm a parcela preponderante do poder (AGUIAR, 2014). Sob essa ótica, no dito Estado Democrático, a democracia é mera figurante.

Não há como desassociar democracia e liberdade política. Um indivíduo só é politicamente livre quando não apenas integra a ordem jurídica, mas participa de sua formação, tendo sua vontade representada pelo Estado (SANTANO; JUNIOR, 2017). Entretanto, aqueles detentores do poder econômico e formal - uma minoria numérica - tendem a dominar o poder político e todo o aparato estatal, retendo, consequentemente, a faculdade de legislar. Assim, a parcela majoritária da sociedade constitui minoria do poder, ficando às margens das tomadas de decisão do país, tendo suas pautas sub-representadas, e ocupando a periferia do "ideal democrático". Por conseguinte, a classe a que o sujeito pertence influencia concretamente seus direitos e deveres, bem como sua igualdade maior ou menor, e o tamanho de sua fatia no bolo do poder.

\subsection{DIREITO COMO EXPRESSÃO DO PODER}

Neste cenário, o Direito surge como ferramenta, principalmente, de manutenção do status quo. Da mesma forma que a ordem jurídica se destina aos grupos sociais, ela emerge destes grupos (AGUIAR, 2014). Em consequência, os donos do poder sustentados, ativa ou passivamente, pela já citada ala periférica legislam a favor de si mesmos para manter seu posto, e contra outros grupos para controlá-los. Dessa forma, os indivíduos se encontram à mercê de sua posição social, que determina o nível de incidência da normatividade jurídica sobre eles, assim como de imersão na relação dominante-dominado. Esta relação, por sua vez,

[...] se põe como consequência última das normas que são promulgadas para manter o poder, a unidade social e a estabilidade conforme os padrões de quem legisla. De quem determina o "dever-ser" da sociedade. Os grupos a que um indivíduo pertence possibilitam concretamente seus direitos e seus deveres, orwellianamente, a sua igualdade maior ou menor (AGUIAR, 2014, p. 35).

À vista disso, o Direito figura como a mais alta expressão ideológica do poder, ditando os princípios, as condutas, defendendo certas ações e sancionando outras. Não se pode falar em Direito neutro, abstrato. O arsenal jurídico-normativo é fruto de um regime político, de um governo; ou seja, de pessoas pertencentes a determinados grupos sociais que, uma vez instituídas a partir de suas respectivas posições na escala produtiva, pensam em conformidade com estes. De tal maneira, para a manutenção do poder e para se manter como aparato de controle social, o Estado edita normas que 
refletem a ideologia do poder, "tornando-as ativas e seletivas, por meio de um dever-ser sancionador que regula, controla e promove condutas" (AGUIAR, 2014, p. 85).

Sob este espectro, não é de se espantar a cristalização, enrijecimento e rigor do Direito e de suas normas, bem como da maioria de seus operadores; a verdade jurídica não passa, portanto, do reflexo máximo do conteúdo ideológico do poder vigente. Mas esta não é uma relação unilateral; o vínculo direito-poder é dinâmico, e está longe do mero exercício jurídico em defesa de direitos. Os grupos dominantes, integrantes da maior parte da máquina estatal, lançam mão de todos os meios para a manutenção do poder, criando mecanismos de autopromoção, propaganda e controle no plano extrajurídico; e à nível jurídico, arquitetando punições eficazes para ações que ameacem a segurança de seus interesses. Nessa esfera, os majoritários sem poder ficam à deriva. De acordo com Roberto Aguiar (2014),

[...] no Brasil, por exemplo, o direito penal sanciona aqueles que não têm condições de se defender, o direito civil no âmbito das obrigações sempre faz as sanções recaírem sobre aqueles que, por alguma razão, feriram as regras do capitalismo, tornando-se insolventes, solventes que não pagam bem ou não cumpridores de obrigação. Em termos simples: quem não tem dinheiro ou não soube administrá-lo sofre a sanção civil (AGUIAR, 2014, p. 208).

A partir disso, é evidente que o Direito, mesmo que tente sustentar os ideais de justiça e democracia, cede ao capital. Direitos são relativizados e a própria justiça também: o que é direito de cada um? Até onde vai a liberdade de expressão e quando esta se transfigura em discursos e declarações de caráter odioso? Honestidade segundo que valores? Justiça para quem? Para o patrão para ou para o trabalhador? Se a democracia é o governo emanado do povo, o equilíbrio da balança deve ser estabelecido. Não se trata da ditadura da maioria e da imposição de valores e crenças, mas da representação de todos que, ao acordarem a legitimidade do Estado, depositaram nas mãos de seus representantes a proteção não apenas dos dispositivos constitucionais, mas também dos direitos e garantias fundamentais indispensáveis à dignidade e à vivência plena em sociedade (SANTANO; JUNIOR, 2017).

\subsection{ABUSO DE PRERROGATIVAS}

Como já abordado, a protuberante ocupação da máquina estatal pela minoria populacional dominante implica na exclusão dos majoritários sem poder, vítimas de um cerceamento de sua participação política, social e econômica. De mesmo modo, o ordenamento jurídico incide de cima 
para baixo, sobretudo no âmbito do livre debate político, maquiando as desigualdades e calando as vozes daqueles que possam ameaçar seu status. Esse cenário se agrava com a

[...] crescente tendência de invocação da liberdade de expressão para a legitimação de um primitivismo político, traduzido por meio de discurso de ódio. [...] Tais manifestações visam à dominação, à exclusão, à violência, ao afastamento social, e ao emudecimento das vozes dissidentes, ou seja, a redução de um espaço de deliberação plural (BERNADELLI; VARGAS, 2017, p. 307).

O posicionamento liberal defende que todos partem do mesmo ponto, sendo tal "igualdade" suficiente para a configuração da equidade; assim, não haveria de se falar em desproporcionalidade de armas no debate político. Esta concepção, porém, ao desconsiderar as desigualdades das experiências concretas, constitui um sistema defeituoso, em que as vozes ouvidas são aquelas dos donos do poder, que por muitas vezes abusam das prerrogativas que lhes são auferidas pelo cargo. Exemplo disto são as chamadas "prerrogativas parlamentares".

Originárias do direito inglês, as prerrogativas parlamentares traduzem-se na proteção do exercício parlamentar por meio do posto princípio da liberdade para o exercício do mandato. Tal princípio, assim como as prerrogativas, se fazem presentes no ordenamento brasileiro, a partir do modelo de democracia deliberativa republicana adotado pela $\mathrm{CF} / 88$, baseado nos princípios da democracia representativa, do mandato representativo, da fidelidade partidária, e da liberdade de convicção e consciência. Na prática, isso significa que as opiniões, palavras e votos dos parlamentares proferidos em seu mandato podem ser apreciados apenas pelos membros da mesma Casa, no caso, pelo Poder Legislativo (BERNADELLI; VARGAS, 2017).

Não se pode negar que o papel desempenhado pelo Legislativo é imprescindível para a concretização do Estado Democrático de Direito, uma vez que integra uma estrutura representativa para a busca da vontade geral. Por outro lado, as prerrogativas parlamentares são muitas vezes utilizadas como escudo para a proliferação de discursos odiosos pelos representantes da Casa. Essa situação é agravada pela lacuna legislativa no que tange ao estabelecimento dos limites dessas prerrogativas e do momento em que a atividade parlamentar pode ser considerada abusiva. Segundo Bernadelli (2017),

Não é surpresa que no âmbito do parlamento, deputados e senadores, em discursos inflamados, podem desagradar seus opositores. Entretanto, o discurso de ódio transcende a mera expressão de opinião - indispensável ao livre funcionamento do Legislativo - e vai além dos dissabores próprios do exercício da atividade parlamentar. Tais discursos constituem uma prática discriminatória de forma verbal. Isso porque, sendo a subjetividade individual formada a partir das identidades sociais, tais falas reafirmam sobre o ofendido as relações de subordinação impostas pela própria sociedade, visando, não só destruir suas 
identidades, como também retirar-lhes a capacidade de expressão (BERNADELLI; VARGAS, 2017, p. 321).

Com isto em vista, é inegável que o jogo político paira sobre os seletos membros do Legislativo, contribuindo para o sufocamento ainda maior das vozes marginais. A liberdade de expressão torna-se uma faca de dois gumes: ao passo que vários dos discursos proferidos exaltam a força da igualdade, aqueles que os proferem se negam a consagrá-la.

\subsection{OPINIÃO PÚBLICA E DISCURSOS DE ÓDIO}

Em 2014, entrou em discussão o Projeto de Lei $n^{\circ}$ 6583/2013 com o intuito de criar o Estatuto da Família. Em enquete realizada pela Câmara dos Deputados, 48,9\% das pessoas que responderam à pesquisa (4.944.827 votos) concordaram com a definição de família apresentada pelo Projeto: núcleo formado a partir da união entre um homem e uma mulher ${ }^{3}$. Ainda que numericamente a opinião pública favorável a esta definição represente uma minoria, tal dado é alarmante. Desconsiderando totalmente o reconhecimento pelo Supremo Tribunal Federal em 2011 da união entre pessoas do mesmo sexo como entidade familiar, bem como o art. $3^{\circ}$ da Constituição, que proíbe a discriminação, o Projeto representa um retrocesso na salvaguarda de direitos fundamentais.

Durante as discussões na Comissão Especial formada para debater o Projeto, o deputado Eduardo Bolsonaro afirmou que a cirurgia de resignação de sexo é análoga a um crime. Ademais, o então deputado e hoje Presidente da República, Jair Bolsonaro associou a defesa de direitos LGBTQI+ à defesa de práticas pedófilas. São declarações como essas que disfarçadas de liberdade de expressão comprovam a necessidade do estabelecimento de limites mais justos e exatos às prerrogativas parlamentares.

Tão problemática quanto a proposição de um Projeto desse caráter por um dos órgãos instituídos para a representação dos cidadãos, é a constatação de que quase cinco mil pessoas são coniventes com a redação proposta. Deste modo, tal "opinião pública" consonante aos discursos de ódio favorece o uso dos cargos de poder para a proliferação de ideias hostis à democracia, mascaradas de respostas às demandas da maioria (BERNADELLI; VARGAS, 2017).

Neste cenário, a tríade discursos versus normas versus práticas é envolvida pelos braços das elites que, ocupando cargos de poder, legislam em favor próprio e de outras elites influentes. Por

\footnotetext{
${ }^{3}$ Dados disponíveis em: https://www2.camara.leg.br/enquetes/pesquisaEnquete. Acesso em: 26 jun. 2020.
} 
meio de discursos muitas vezes falaciosos, o conteúdo da norma jurídica é deturpado, levando a práticas que atentam contra os direitos daqueles às margens do poder. Em um país desigual e multifacetado como o Brasil, não se pode dizer que existe uma única elite. Na verdade, há uma elite predominante, a elite do dinheiro, que comanda as demais (intelectual, política, jurídica, jornalística, entre outras) por meio de seu poderio econômico (SOUZA, 2016). Sendo assim, tendo o controle da elite política, mais especificamente o Congresso Nacional, a prática do lobby é corriqueira no sentido de satisfazer os interesses dessa minoria dominante.

Isto posto, é evidente a relação de poder entre a voz falante e o sujeito de quem se fala. Assim, o estabelecimento de contornos à liberdade de expressão não se trata de um reclamo pela censura, mas sim do desejo de que aqueles possuidores do poder tenham responsabilidade na difusão de informações e opiniões.

\subsection{ESTADO DEMOCRÁTICO DE DIREITO: ENTRE A UTOPIA E A REALIDADE}

Evidenciou-se até aqui a complexa relação de poder entre o Direito e seus aplicadores, e aqueles sobre os quais as normas recaem. Ademais, a relação dominante-dominado faz-se presente em toda a máquina estatal, influenciando o movimento de todos as suas peças. Assim, o ideal do Estado Democrático de Direito é utilizado como cortina de fumaça, enquanto na realidade a democracia é ameaçada e os direitos fundamentais violados.

Ora, frente ao enrijecimento e à cristalização do Direito posto, não se pode esperar que a luta pelo Estado de Direito se dê no íntimo do ordenamento jurídico, na medida em que ele aprece como

[...] fruto da relação entre os homens, relação mediada pela produção e produção mediada pela opressão. Buscar o Estado de direito significa luta política, pois essa busca só irá ter eficácia se as bases das relações sociais forem solapadas, desencadeando assim a mudança dos fundamentos normativos. A bem da verdade, não se luta por um Estado de direito, lutase, isto sim, pela transformação social que engendrará um novo direito. O Estado de direito é o novo direito e o novo direito significaria reconhecimento em oposição à dominação (AGUIAR, 2014, p. 168).

Neste sentido, é importante resgatar o Estado Democrático de Direito em sua forma mais pura: um Estado cujo objetivo é livrar o direito posto "das marcas da arbitrariedade, da autocracia, da discriminação, da punição inconsequente, da facilitação da concentração da renda e da propriedade [...]" (AGUIAR, 2014, p. 168). Infelizmente, o desenho democrático brasileiro ainda não é esse. A democracia não pode significar meramente um conjunto de instituições; mas deve ser 
um instrumento que possibilite invocar, quando necessário, a Constituição e demais elementos do ordenamento jurídico para equilibrar a balança, em oposição à desigualdade entre os donos do poder e os majoritários sem voz (BERNADELLI; VARGAS, 2017).

Enquanto as normas jurídicas servirem tão-somente para a manutenção do status quo, para o fortalecimento dos instrumentos de controle e repressão do poder, para podar os direitos de seus destinatários, e enquanto a limitação do poder for injusta, ter-se-á um Direito que não se presta ao seu papel; um Direito que ao não dar ouvidos às vozes marginais não está servindo aos interesses predominantes de uma sociedade (AGUIAR, 2014). Enquanto isso acontecer, o Estado Democrático de Direito não passará de mera utopia.

\section{CONSIDERAÇÕES FINAIS}

Pelo exposto, o resgaste histórico e conceitual se faz necessário para melhor compreender o Estado Democrático de Direito brasileiro, bem como as bases constitucionais que regem o ordenamento jurídico-normativo nacional. Neste sentido, analisou-se a teoria dos direitos fundamentais inerentes à democracia frente à realidade vivenciada em solo pátrio.

Como demonstrado, é possível observar que - apesar do amplo arsenal normativo no que diz respeito à promoção, proteção e efetivação dos direitos e garantias fundamentais - o Direito cede ao capital. Os donos do poder com a intenção de manter suas posições privilegiadas na escala produtiva fazem uso da máquina estatal em benefício próprio, legislando em seu favor e em detrimento dos majoritários sem voz. Neste cenário, a democracia fica em segundo plano, sendo utilizada como cortina de fumaça para os interesses dos dominantes e seu poder ante aos dominados.

De tal modo, a não efetivação dos direitos fundamentais constitui não apenas desrespeito a um plano de governo, mas à própria finalidade do Estado Democrático de Direito, fazendo da Constituição mera letra morta.

\section{REFERÊNCIAS}

AGUIAR, Roberto. Direito, poder e opressão. 2 ed. Rio de Janeiro: Lumen Juris, 2014. 
ARAUJO, Luiz Alberto David; NUNES JÚNIOR, Vidal Serrano. Curso de Direito Constitucional. 19. ed. São Paulo: Verbatim, 2015.

BERCOVICI, Gilberto. Constituição e política: uma relação difícil. Lua Nova, São Paulo, n. 61, p. 5-24, 2004. Disponível em: https://www.scielo.br/scielo.php?pid=S010264452004000100002\&script=sci_abstract\&tlng=pt. Acesso em: 25 jun. 2020.

BERNARDELLI, Paula; VARGAS, Tuany Baron de. Manifestações de ódio no exercício da atividade parlamentar: liberdades de discurso e abuso de prerrogativas. In: SALGADO, Eneida Desiree; HACHEM, Daniel Wunder (org.). Direito, liberdade e justiça. Curitiba: Editora Íthala, 2017. p. 305-329.

BONAVIDES, Paulo. Curso de direito constitucional. 34. ed. São Paulo: Malheiros, 2019.

. Teoria do Estado. 6. ed. São Paulo: Malheiros, 2007

BRASIL. Constituição da República Federativa do Brasil de 1988. Brasília, DF, 5 out. 1988.

FACHIN, Zulmar. Curso de direito constitucional. 3. ed. São Paulo: Método, 2008.

FRANÇA. Assembleia Nacional Constituinte Francesa. Declaração de Direitos do Homem e do Cidadão. Versalhes, França, 26 ago. 1979.

GOMES, Sergio Alves. Hermenêutica Jurídica e Constituição no Estado de Direito Democrático. 2. ed. Rio de Janeiro: Forense, 2002.

MARMELSTEIN, George. Curso de direito fundamentais. 5. ed. São Paulo: Atlas, 2014.

SANTANO, Ana Claudia; JUNIOR, Wilson Trindade. O direito de decidir: entre a liberdade de escolha e a intervenção estatal. In: SALGADO, Eneida Desiree; HACHEM, Daniel Wunder (org.). Direito, liberdade e justiça. Curitiba: Editora Íthala, 2017. p. 11-59.

SARLET, Ingo Wolfgang. A eficácia dos direitos fundamentais: uma teoria geral dos direitos fundamentais na perspectiva constitucional. 10. ed. Porto Alegre: Livraria do Advogado, 2009.

SOUZA, Jessé. A radiografia do golpe: entenda como e por que você foi enganado. Rio de Janeiro: LeYa, 2016. 